\title{
Detecção de Toxoplasma gondii em órgãos do sistema reprodutivo de carneiros naturalmente infectados no Brasil ${ }^{1}$
}

\author{
Mauro José Gonçalves Bezerra², Jefferson Ayrton Leite de Oliveira $\mathrm{Cruz}^{3}$, Eugênio de \\ Souza Kung 3 , Renata Pimentel Bandeira de $\mathrm{Melo}^{3}$, Ana Lisa do Vale Gomes ${ }^{3}$, Érica Paes \\ Barreto Xavier de Moraes ${ }^{4}$, José Wilton Pinheiro Junior ${ }^{4}$ e Rinaldo Aparecido Mota ${ }^{3 *}$
}

\begin{abstract}
Bezerra M.J.G., Cruz J.A.L.O., Kung E.S., Melo R.P.B., Gomes A.L.V., Moraes E.P.B.X., Pinheiro Junior J.W. \& Mota R.A. 2013. [Detection of Toxoplasma gondii in the reproductive organs of rams in Brazil.] Detecção de Toxoplasma gondii em órgãos do sistema reprodutivo de carneiros no Brasil. Pesquisa Veterinária Brasileira 33(8):989-991. Laboratório de Doenças Infectocontagiosas dos Animais Domésticos, Universidade Federal Rural de Pernambuco, Rua Dom Manoel de Medeiros s/n, Recife, PE 52171-900, Brazil. E-mail: rinaldo.mota@hotmail.com

The aim of the study was to detect genomic DNA of Toxoplasma gondii in testicle and epididymis samples from rams sold in abattoirs in the state of Pernambuco, Northeast Brazil. Fifty (50) blood serum samples were collected, as well as 50 testicle and epididymis samples. Indirect Immunofluorescence (IIF) was used during screening of the rams. The Polymerase Chain Reaction (PCR) was used with animals that were positive in serology. Our results confirmed that $24 \%(12 / 50)$ of the rams were positive in IIF. Genomic DNA was detected in the epididymis at $8.3 \%(1 / 12)$ of the animals. The molecular identity of the amplified products was confirmed through sequencing. This paper reports the first occurrence of $T$. gondii DNA in the reproductive organs of naturally infected rams in Brazil.
\end{abstract}

INDEX TERMS: Toxoplasmosis, reproductive organs, rams, sheep, Polymerase Chain Reaction (PCR).

RESUMO.- Objetivou-se com esse estudo detectar o DNA genômico de T. gondii em amostras de testículo e epidídimo de ovinos comercializados em abatedouros do Estado de Pernambuco Região Nordeste do Brasil. Foram coletadas 50 amostras de soro sanguíneo, 50 amostras de testículos e 50 de epidídimos. Para a triagem dos animais foi utilizada a técnica de Imunofluorescência Indireta (RIFI) e posteriormente empregou-se a Reação em Cadeia da Polimerase (PCR) nos animais positivos na sorologia. Observou-se $24 \%(12 / 50)$ dos animais positivos na RIFI e o DNA genômico foi detectado no epidídimo em 8,3\% (1/12) das amostras. A identidade molecular dos produtos am-

\footnotetext{
${ }^{1}$ Recebido em 17 de maio de 2013.

Aceito para publicação em 8 de julho de 2013.

${ }^{2}$ Superintendência de Desenvolvimento do Nordeste (SUDENE), Praça Ministro João Gonçalves de Souza s/n, Engenho do Meio, Recife, PE 50670500, Brasil.

${ }^{3}$ Laboratório de Doenças Infectocontagiosas dos Animais Domésticos Universidade Federal Rural de Pernambuco, Rua Dom Manoel de Medeiros s/n, Dois Irmãos, Recife, PE 52171-900. *Autor para correspondência: rinaldo.mota@hotmail.com

${ }^{4}$ Unidade Acadêmica de Garanhuns, Universidade Federal Rural de Pernambuco, Av. Bom Pastor s/n, Boa Vista, Garanhuns, PE 55292-270, Brasil.
}

plificados foi confirmada por sequenciamento. Relata-se a primeira ocorrência da presença do DNA de T. gondii em órgãos do sistema reprodutivo de carneiros naturalmente infectados no Brasil.

TERMOS DE INDEXAÇÃO: Toxoplasmose, órgãos de reprodutivos, carneiros, ovinos, PCR.

\section{INTRODUÇÃO}

O rebanho ovino no Brasil está entre os dez maiores do mundo com um efetivo de mais de 17,4 milhões de cabeças e na Região Nordeste concentram-se aproximadamente 56,7\% do rebanho nacional, ocupando o Estado de Pernambuco o quarto lugar do ranking nacional (IBGE 2010). Contudo, na maioria das explorações no Nordeste Brasileiro, a produtividade ainda é baixa sendo causada principalmente devido aos problemas de sanidade animal (Simplício et al. 2001).

A toxoplasmose é uma importante zoonose de distribuição mundial que causa diversos transtornos reprodutivos em vários hospedeiros intermediários. 0 parasito responsável por essa doença é Toxoplasma gondii, um protozoário com reprodução intracelular obrigatória, podendo ser encontrado nos diferentes exsudatos dos animais infectados 
(Nicolle \& Manceaux 1908, Dubey et al. 1980, 1995, Dubey \& Sharma 1980, Uggla 1986, Underwood \& Rook 1992, Luzon et al. 1997a, Tenter et al. 2000, Kompalic-Cristo et al. 2005).

Em ovinos, a primeira descrição do agente ocorreu por Olafson \& Monlux (1942) nos Estados Unidos, e desde então, inúmeros trabalhos demonstram a importância econômica da infecção nesta espécie como causa de abortos e natimortos, além de servirem de fonte de infecção para o homem e embora seu ciclo de vida seja conhecido desde o final da década de 1960, muitos aspectos relacionados à infecção por T. gondii ainda precisam ser esclarecidos (Freyre et al. 1997, Bastien 2002).

Estudos epidemiológicos recentes realizados em Pernambuco por Peixoto et al. (2006), demonstraram que a infecção por T. gondii encontra-se disseminada nos rebanhos de ovinos, estando diretamente relacionada com falhas reprodutivas, demonstrando a necessidade de se intensificar os estudos sobre a importância da transmissão horizontal do parasito para contribuir com as investigações epidemiológicas, clinicas e reprodutivas na infecção pelo $T$. gondii nesta espécie.

Moraes et al. (2010a) estudaram a infecção natural por T. gondii em carneiros e observaram $9,2 \%$ de positivos na sorologia e na PCR nested, 66,6\% das amostras de sêmen foram positivas. Concluíram que a detecção da forma proliferativa de T. gondii no sêmen de carneiros naturalmente infectados reforça a necessidade de se pesquisar a possibilidade da transmissão horizontal do parasito na espécie ovina.

Objetivou-se com esse estudo detectar o DNA genômico de T. gondii em amostras de testículo e epidídimo de carneiros naturalmente infectados e abatidos em matadouros no Estado de Pernambuco, Brasil.

\section{MATERIAL E MÉTODOS}

Amostras de soro sanguíneo e de órgãos do sistema reprodutivo. Nos anos de 2010 e 2011 foram coletadas 50 amostras de soro sanguíneo, 50 amostras de epidídimo e 50 de testículo de reprodutores ovinos de diferentes raças e idades em matadouros no Estado de Pernambuco, Brasil. Os ovinos eram procedentes de criações comerciais situadas na região Agreste do estado de Pernambuco.

Sorologia. Utilizou-se a RIFI como triagem para detectar os animais positivos que foram posteriormente utilizados para a realização da PCR. Para a detecção de anticorpos IgG anti-Toxoplasma gondii foi empregada a RIFI de acordo com o protocolo preconizado por Camargo (1964), utilizando-se anticorpos anti-IgG-ovino $\left(\right.$ Sigma $^{\circledR}$ ) conjugado ao isotiocianato de fluoresceína, com ponto de corte 64, utilizando-se como antígeno, taquizoítos da cepa RH. Em todas as reações foram incluídos controle positivo e negativo, previamente conhecidos.

Exame molecular para detecção de DNA de Toxoplasma gondii. As amostras de testículo e epidídimo foram submetidas à extração de DNA, utilizando-se Kit comercial Wizard Genomic DNA Purification (Promega ${ }^{\circledR}$ ), seguindo o protocolo do fabricante. Os pares iniciadores utilizados foram TOX4 (CGCTGCAGGGAGGAAGACGAAAGTTG) e TOX5 (CGCTGCAGACACAGTGCATCTGGATT) segundo Homan et al. (2000), amplificando uma região de 529 pares de base (pb). As reações de amplificação foram realizadas em um volume final de $12,5 \mu \mathrm{L}$ contendo: $2,5 \mu \mathrm{L}$ de DNA genômico;
$0,5 \mu \mathrm{L}$ de cada primer (TOX4 e TOX5) à $10 \mu \mathrm{M} ; 2,5 \mu \mathrm{L}$ de Água Mili-Q ultrapura e 6,25 $\mu \mathrm{L}$ de Top Taq Master Mix (Quiagen ${ }^{\circledR}$ ), de acordo com o protocolo do fornecedor. 0 perfil térmico das etapas de reações foi feito em um termociclador XP Thermal Cycler (Bioxer Technology Co. Ltda), consistindo de uma desnaturação do DNA inicial a $94^{\circ} \mathrm{C}(7 \mathrm{~min})$ e seguida de 35 ciclos a $94^{\circ} \mathrm{C}$ por 1 minuto para a desnaturação, $60^{\circ} \mathrm{C}$ por 1 minuto para o anelamento, $72^{\circ} \mathrm{C}$ por 1 minuto para a extensão e extensão final de 10 minutos a $72^{\circ} \mathrm{C}$. Os produtos amplificados foram detectados por eletroforese em gel de agarose a $2 \%$, corados com Blue Green (LGC ${ }^{\circledR}$ ), visualizados através de luz ultravioleta e fotodocumentados. 0 controle positivo utilizado na reação foi obtido por meio de suspensão de lavados intraperitoneais de camundongos previamente infectados com a cepa RH.

Para o sequenciamento, os produtos amplificados foram purificados empregando kit comercial GFXTM PCR DNA e kit de purificação de bandas em gel de agarose GE Healthcare. Utilizou-se o sequenciador ABI PRISM 3100 (Applied Biosystems), as reacções foram realizadas em ambas as cadeias utilizando iniciadores (TOX4 e TOX5) de acordo com o Big Dye Terminator v3.1 Cycle Sequencing Kit (Applied Biosystems) e as condições de polimerização foram realizadas em placas de 96 poços de acordo com as instruções do fabricante. As sequências foram analisadas através BIOEDIT e MEGA 5 software e comparadas com o banco de dados do NCBI usando BLAST.

\section{RESULTADOS}

Na sorologia, foram detectados 12/50 (24\%) amostras positivas. Na PCR realizada nas amostras de testículo e epidídimo dos doze animais positivos na sorologia, detectou-se o DNA de T. gondii em uma amostra de epidídimo (01/12), correspondendo a $8,33 \%$. A identidade molecular foi confirmada através do sequenciamento de fita dupla direta que indicou $99,9 \%$ de similaridade com as sequências de DNA de T. gondii armazenados no GENBANK (DQ779196.1).

\section{DISCUSSÃo}

Este estudo é pioneiro no que se refere à detecção de DNA de Toxoplasma gondii em órgão reprodutivo (epidídimo) de carneiro naturalmente infectado. Outros estudos realizados anteriormente utilizaram carneiros experimentalmente infectados e demonstraram a presença do parasito em amostras seminais. Spence et al. (1978) realizaram o primeiro isolamento de T. gondii e mais tarde, Aganga et al. (1988) recuperaram T. gondii em amostras de sêmen de $100 \%$ dos carneiros infectados com a cepa TS-1. Teale et al. (1982) também observaram o parasito em amostras de sêmen. Apesar desta observação, até o momento ainda não se comprovou a transmissão do parasito via sêmen na infecção natural.

A busca do parasito em órgãos reprodutivos de carneiros naturalmente infectados realizado neste estudo foi estimulada, em parte, pelos resultados obtidos na infecção experimental realizada por Moraes et al. (2010b) e Moraes et al. (2010c) que infectaram ovelhas com sêmen contaminado com diferentes doses de T. gondii e observaram, através de exames ultrassonográficos, transtornos reprodutivos como reabsorções embrionárias, morte fetal e aborto. 0 estudo comprovou a transmissão do parasito via sêmen experimentalmente contaminado em ovelhas e uma elevada frequência de absorção embrionária, indicando a colonização 
precoce da placenta e embrião no início da gestação, o que demonstrou que este aspecto deveria ser melhor investigado na infecção natural. A presença do DNA de T. gondii em órgãos reprodutivos é um resultado relevante e demonstra a necessidade de outras investigações sobre a repercussão deste achado na infecção natural.

A detecção do DNA de T. gondii no presente estudo não indica necessariamente que este parasito está viável para infectar ovelhas durante a cópula. Para comprovar esta hipótese e sua real importância na reprodução desta espécie é necessário avaliar a quantidade do parasito presente neste órgão e no sêmen e sua viabilidade por meio de bioprova. Neste estudo isso não foi possível, pois os órgãos foram colhidos em matadouros o que dificultou a realização de coletas de amostras de sêmen para a inoculação em camundongos. Em caprinos experimentalmente infectados, Santana et al. (2010) isolaram T. gondii em amostras de sêmen e em amostras de tecido do sistema reprodutivo, utilizando a técnica da PCR e bioprova e sugeriram a possibilidade de transmissão venérea deste coccídeo nesta espécie. 0 isolamento (estudo da viabilidade) e quantificação de T. gondii no sistema reprodutor de ovinos (epidídimo e sêmen) naturalmente infectados poderá sugerir a participação desta via na transmissão do parasito nos rebanhos.

A presença do DNA de T. gondii neste órgão reprodutivo na infecção natural de ovinos ainda necessita de estudos mais detalhados para determinar possíveis alterações andrológicas e reprodutivas. Sobre este aspecto, Terpsidis et al. (2009) em estudos experimentais afirmaram que a infecção experimental por T. gondii pode causar alterações andrológicas e reprodutivas em camundongos. Lopes et al. (2009) também identificaram patologias espermáticas em carneiros experimentalmente infectados, contudo concluíram que estas poderiam não estar relacionadas à infecção por T. gondii.

Neste estudo não foi possível estimar a fase da infecção e se os animais estavam eliminando o parasito no sêmen. A detecção de T. gondii em amostra de epidídimo em ovino naturalmente infectado estimula a realização de estudos sobre outras vias de transmissão nesta espécie.

\section{REFERÊNCIAS}

Aganga A.A., Alabi O. \& Momoh M. 1988. Effect of water deprivation on nutrient digestibility, nitrogen retention, and water excretion in Yankasa sheep and Maradi goats. Nigerian J. Anim. Prod. 15:139-143.

Bastien P. 2002. Diagnosis molecular: diagnosis of toxoplasmosis. Trans. Royal Soc. Trop. Med. Hygiene 96(1):205-215.

Camargo M.E. 1964. Introdução às técnicas de imunofluorescência. Revta Bras. Patol. Clín. 10:143-71.

Dubey J.P. \& Sharma S.P. 1980. Prolonged excretion of Toxoplasma gondii in semen of goats. Am. J. Vet. Res. 41(5):794-795.

Dubey J.P., Sharma S.P., Lopes C.W.G., Williams J.F., Williaors C.S.F. \& Weisbrode S.E. 1980. Caprine toxoplasmosis: abortion, clinical, signs, and distribution of Toxoplasma in tissues of goats fed Toxoplasma gondii oocysts. Am. J. Vet. Res. 41:1072-1076.

Freyre A., Bonino J., Falcon J., Castells D., Correa O. \& Casaretto A. 1997.
The incidence and economic significance of ovine toxoplasmosis in Uruguay. Vet. Parasitol. 73(1/2):13-15.

Homan W.L., Vercammen M., De Braekeleer J. \& Verschueren H. 2000. Identification of a 200- to 300 -fold repetitive 529 bp DNA fragment in Toxoplasma gondii, and its use for diagnostic and quantitative PCR. Int. J. Parasitol. 30(1):69-75.

IBGE 2010. Diretoria de Pesquisas, Coordenação de Agropecuária, Pesquisa da Pecuária Municipal 38, Tabela 17.

Kompalic-Cristo A., Britto C. \& Fernandes O. 2005. Diagnóstico molecular da toxoplasmose: revisão. J. Bras. Patol. Med. Lab., Rio de J., 41(4):229235.

Lopes W.D.Z., Costa A.J., Souza F.A., Rodrigues J.D.F., Costa G.H.N., Soares V.E. \& Silva G.S. 2009. Semen variables of sheep (Ovis aries) experimentally infected with Toxoplasma gondii. Anim. Reprod. Sci. 111:312-319.

Luzon M., Alonso A. \& Quintanilla-Gozalo A. 1997. Etiologia y biologia: toxoplasmosis. Revta Ovis, Tratado de Patologia y Produccion Ovina, Madrid, 52:11-17.

Moraes, E.P.B.X., Faria E.B., Batista A.M., Freitas A.C., Silva J.C.R., Albuquerque P.P.F. \& Mota R.A. 2010a. Toxoplasma gondii detection in the semen of naturally infected sheep. Pesq. Vet. Bras. 30(11):915-917.

Moraes E.P.B.X., Batista A.M., Faria E.B., Freire R.L., Freitas A.C., Silva M.A.R., Braga V.A. \& Mota R.A. 2010b. Experimental infection by Toxoplasma gondii using contaminated semen containing different doses of tachyzoites in sheep. Vet. Parasitol. 170:318-322.

Moraes E.P.B.X., Freitas A.C., Gomes-Filho M.A., Guerra M.M.P., Silva M.A.R., Pereira M.F., Braga V.A. \& Mota R.A. 2010c. Characterization of reproductive disorders in ewes given anintrauterine dose of Toxoplasma gondii tachyzoites during the intrauterine insemination. Anim. Reprod. Sci. 122:36-41.

Nicolle C. \& Manceaux L. 1908. Sur une infection à corps de Leishman (ou organimes voisins) du gondii. Clin. Rev. Acad. Sci., Paris, 147:763-766.

Olafson P. \& Monlux W.S. 1942. Toxoplasma infection in animals. Cornell Vet., Ithaca, 32(2):176-190.

Peixoto R.M., Pereira M.F. \& Mota R.A. 2006. Participação de Toxoplasma gondii em falhas reprodutivas nas espécies ovina e caprina no Estado de Pernambuco, p.93-104. In: Albuquerque U.P., Véras A.S.C., Freire F.J. \& Lira Júnior M.A. (Eds), Caminhos da Ciência. Vol.1. Editora Universitária, UFRPE, Recife.

Santana L.F., Costa A.J., Pieroni J., Lopes W D.Z., Santos R.S., Oliveira G.P., Mendonça R.P. \& Sakamoto C.A.M. 2010. Detection of Toxoplasma gondii in the reproductive system of male goats. Revta Bras. Parasitol. Vet. 19(3):179-182.

Simplício A.A., Salles H.O., Santos D.O. \& Azevedo H.C. 2001. Manejo reprodutivo de caprinos e ovinos de corte em regiões tropicais. Doc.35, Embrapa Caprinos. Sobral, p.47.

Spence J.B., Beattie C.P., Faulkner J., Henry L. \& Watson W.A. 1978. Toxoplasma gondii in the semen of rams. Vet. Rec. 14(102):38-39.

Teale A.J., Blewett D.A., Miller J.K. \& Buxton D. 1982. Experimentally induced toxoplasmosis in young rams: the clinical syndrome and semen secretion of Toxoplasma. Vet. Rec. 17(111):53-55.

Tenter A.M., Heckeroth A.R. \& Weiss L.M. 2000. Toxoplasma gondii: from animals to humans. Int. J. Parasitol. 30(12/13):1217-1258.

Terpsidis K.I., Papazahariadou M.G., Taitzoglou I.A., Papaioannou N.G., Georgiadis M.P. \& Theodoridis I.T. 2009. Toxoplasma gondii: reproductive parameters in experimentally infected male rats. Exp. Parasitol. 121:238-241.

Uggla A. 1986. Toxoplasma gondii in farm animals: some immunodiagnostic methods and their potential use. Merkantil-Tryckeriet, Uppsala, p.1-56.

Underwood W.J. \& Rook J.S. 1992. Toxoplasmosis infection in sheep. Comp. Cont. Educ. Pract. Vet. 14:1543-1549. 